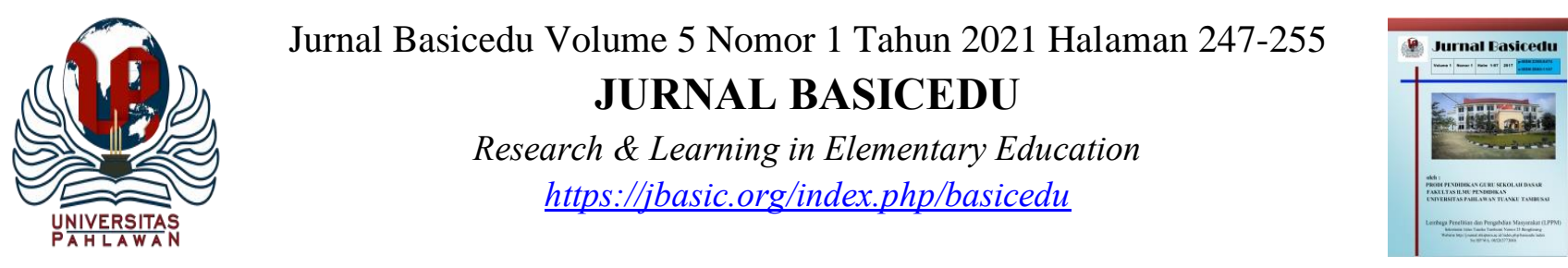

\title{
Pengaruh Bimbingan Belajar terhadap Hasil Belajar Bahasa Indonesia Siswa Kelas Tinggi di Sekolah Dasar
}

\author{
Hani Subakti ${ }^{1}$ Eka Selvi Handayani ${ }^{2}$ \\ Universitas Widya Gama Mahakam Samarinda, Indonesia ${ }^{1,2}$ \\ E-mail: hanisubakti@,uwgm.ac.id ${ }^{1} \underline{\text { ekaselvi@uwgm.ac.id }}^{2}$
}

\begin{abstract}
Abstrak
Kegiatan bimbingan belajar memiliki pengaruh cukup signifikan terhadap hasil belajar Bahasa Indonesia siswa kelas tinggi sekolah dasar di Kota Samarinda. Bimbingan belajar dapat dijadikan tolok ukur keberhasilan belajar bagi para siswa sekolah dasar. Sementara itu hasil belajar Bahasa Indonesia dapat dipengaruhi oleh beberapa faktor di antaranya faktor internal dan faktor eksternal siswa. Penelitian ini memiliki titik fokus pada bimbingan belajar yang mempengaruhi hasil belajar Bahasa Indonesia siswa kelas V di SD Negeri 002 Sungai Pinang Kota Samarinda. Penelitian ex post facto ini dilakukan karena tidak ada kontrol terhadap variabel bebas dan peneliti tidak mengadakan pengaturan atau manipulasi terhadap variabel bebas. Penelitian ini terdiri atas dua variabel yaitu satu variabel bebas dan satu variabel terikat. Variabel bebas dalam penelitian ini adalah bimbingan belajar (X). Sedangkan variabel terikatnya adalah hasil belajar Bahasa Indonesia (Y). Berdasarkan hasil penelitian dan hasil analisis dapat diketahui dari hasil perhitungan uji hipotesis $\mathrm{T}$. Adapun hasil yang diperoleh menyatakan bahwa hasil bimbingan belajar dan hasil belajar Bahasa Indonesia $\mathrm{T}_{\text {hitung }}$ adalah 4,451 dengan $\mathrm{T}_{\text {tabel }}$ 1,701. Sehingga dapat ditulis bahwa $\mathrm{T}_{\text {hitung }}<\mathrm{T}_{\text {tabel }}(4,451<1,701)$. Dapat diartikan $H a$ diterima pada hasil angket bimbingan belajar dan hasil belajar bahasa Indonesia. Dengan demikian maka didapatkan $\mathrm{T}_{\text {hitung }}$ adalah 2,541 dengan $\mathrm{T}_{\text {tabel }}$ 1,701. Sehingga dapat ditulis $\mathrm{T}_{\text {hitung }}<\mathrm{T}_{\text {tabel }}(2,541<1,701)$ yang dapat diartikan $H a$ diterima. Berdasarkan perhitungan, dapat disimpulkan hasil angket bimbingan belajar dan hasil belajar Bahasa Indonesia diterima. Jadi secara umum terdapat pengaruh bimbingan belajar terhadap hasil belajar Bahasa Indonesia siswa kelas tinggi di SD Negeri 002 Sungai Pinang tahun pembelajaran 2019/2020.
\end{abstract}

Kata kunci: bimbingan belajar, hasil belajar, Bahasa Indonesia, kelas tinggi

\section{Abstract}

The tutoring activities have a significant influence on the learning outcomes of Indonesian high school students in Samarinda City. Tutoring can be a benchmark for learning success for elementary school students. Mean while, the results of learning Indonesian language can be influenced by several factors including internal factors and external factors of students. This research has a focal point on tutoring that affects the learning outcomes of Indonesian grade $V$ students at SD Negeri 002 Sungai Pinang Samarinda City. This ex post facto study was outrageous because there was no control over free variables and researchers did not conduct any regulation or manipulation of free variables. This research consists of two variables namely one free variable and one bound variable. The free variable in this study is tutoring (X). While the bound variable is the result of learning Indonesian (Y). Based on the results of research and analysis results can be known from the results of the calculation of hypothesis test $T$. The results obtained stated that the results of learning guidance and the results of learning Indonesian $T_{\text {count }}$ is 4,451 with $T_{\text {table }} 1,701$. So it can be written that $T_{\text {count }}<T_{\text {table }}(4,451<1,701)$. Ha can be interpreted as being accepted on the results of the questionnaire of learning guidance and the results of learning Indonesian. Thus $T_{\text {count }}$ obtained is 2,541 with $T_{\text {table }} 1,701$. So it can be written $T_{\text {count }}$ $<T_{\text {table }}(2,541<1,701)$ which can be interpreted Ha accepted. Based on the calculation, it can be concluded that the results of the questionnaire of learning guidance and the results of learning Indonesian language are accepted. So in general there is an influence of tutoring on the learning outcomes of Indonesian high school students at SD Negeri 002 Sungai Pinang in the 2019/2020 learning year.

Keywords: tutoring, learning outcomes, Indonesia language, high class

Copyright (c) 2021 Hani Subakti, Eka Selvi Handayani

$\triangle$ Corresponding author :

Address : Jalan Banggeris 7 No 30 Kota Samarinda

Email : hanisubakti@uwgm.ac.id

ISSN 2580-3735 (Media Cetak)

DOI: https://doi.org/10.31004/basicedu.v5i1.648

ISSN 2580-1147 (Media Online) 
248 Pengaruh Bimbingan Belajar terhadap Hasil Belajar Bahasa Indonesia Siswa Kelas Tinggi Sekolah Dasar di Kota Samarinda- Hani Subakti, Eka Selvi Handayani

DOI: https://doi.org/10.31004/basicedu.v5i1.648

\section{PENDAHULUAN}

Belajar adalah proses dalam usaha memperoleh kepandaian atau ilmu kognitif sehingga berakibat pada kematangan. Adanya perubahan pada diri siswa meliputi sikap, keterampilan, kecakapan, dan kemampuan. Oleh karena itu belajar merupakan proses yang aktif pada tujuan, proses melalui pengalaman, serta melihat, mengamati, dan memahami sesuatu. Cara lain untuk mendukung proses belajar dapat diadaptasikan dengan karakteristik karena siswa merupakan subjek belajar itu sendiri (Hamalik, 2011).

Siswa adalah manusia yang menduduki bagian sentral di dalam kegiatan belajar mengajar. Siswa menjadi faktor penentu sehingga dapat mempengaruhi segala hal yang diperlukan untuk mencapai tujuan belajarnya. Di sisi lain pendidik memiliki tanggung jawab untuk mengoptimalkan perkembangan siswa baik pribadi, sosial, dan akademik. Siswa di sekolah memiliki permasalahan yang berbeda-beda tidak hanya masalah sosial tetapi masalah dalam belajar pada proses kegiatan belajar di kelas. Masalah itu seperti lambat menyerap materi pembelajaran, prestasi belajar rendah, tidak dapat menyelesaikan tugas yang diberikan, hingga akhirnya tidak tercapainya hasil belajarnya.

Pada dasarnya pendidikan tidak hanya dilakukan di sekolah, pendidikan dapat dilakukan di luar sekolah. Sebagai pendidik dapat menambahkan kegiatan bimbingan belajar yaitu tambahan belajar setelah berakhirnya jam sekolah.

Kegiatan bimbingan belajar berguna untuk membantu siswa melewati dan menyelesaikan masalah yang berkaitan dengan pembelajaran. Kegiatan bimbingan belajar yang diikuti oleh siswa dilakukan pada jam berakhirnya pelajaran sekolah. Wali kelas mengambil andil penting dalam meningkatkan hasil belajar siswa, yaitu dengan memberikan bimbingan belajar guna menolong siswa memecahkan masalah pembelajaran dan meningkatkan hasil belajar siswa yang rendah. Bimbingan belajar tidak hanya untuk siswa yang memiliki daya serap rendah. Siswa yang memiliki daya serap normal atau di atas rata-rata juga perlu untuk mengasah pengetahuan yang mereka peroleh di sekolah.

Hasil belajar merupakan perubahan sikap serta kebiasaan menyeluruh yang dipunya siswa baik berupa pengetahuan, sikap, serta pengalaman. Hasil belajar termasuk sebuah prestasi yang diraih siswa dari kerja keras yang berbentuk pengetahuan dan kebisaan yang ada pada penilaian sikap, kecakapan dasar, dan perubahan tingkah laku (Jihad, 2013). Selesainya kegiatan belajar, siswa mendapat nilai, dan hasil belajar memiliki peran penting dalam kegiatan pembelajaran.

Hal pertama yang ingin diraih di dalam kegiatan belajar adalah hasil belajar. Hasil belajar sangat berguna untuk mengetahui sejauh mana siswa bisa memahami serta mengerti materi ajar yang disampaikan oleh pendidik. Nilai sebagai bentuk pengukuran berupa angka, berhuruf, ataupun deskripsi yang menceritakan hasil akhir siswa. Peneliti telah melakukan observasi awal dan mendapatkan informasi mengenai permasalahan yang terlihat di kelas tinggi pada kelas V SD Negeri 002 Sungai Pinang, bahwa tidak semua 
249 Pengaruh Bimbingan Belajar terhadap Hasil Belajar Bahasa Indonesia Siswa Kelas Tinggi Sekolah Dasar di Kota Samarinda- Hani Subakti, Eka Selvi Handayani

DOI: https://doi.org/10.31004/basicedu.v5i1.648

siswa mengikuti kegiatan bimbingan belajar yang dilaksanakan setelah berakhirnya pelajaran.

Bimbingan belajar adalah kegiatan yang dilakukan untuk membantu siswa menyelesaikan masalah dalam hal belajar. Bimbingan belajar dilakukan dengan suasana belajar-mengajar yang kondusif agar terhindar dari kesulitan belajar. Pembimbing dalam bimbingan belajar membantu siswa mengatasi kesulitan belajar, mengembangkan suasana belajar yang efektif, membantu siswa agar berhasil dalam belajar agar mampu menyesuaikan diri terhadap tuntutan pendidikan (Yusuf, 2013). Bimbingan belajar dimaksudkan sebagai cara belajar yang tepat dan menentukan isi pelajaran yang sesuai, untuk menangani kesulitan belajar yang dialami siswa. Secara singkat bimbingan belajar adalah pertolongan yang diberikan bagi individu atau kelompok dalam menyelesaikan masalah-masalah belajar yang dilaksanakan di luar jam pelajaran di sekolah, yang secara langsung dibimbing oleh wali kelas (Purwanto, 2015).

Menurut Arikunto, (2013) hasil belajar suatu hal yang menjadi milik siswa selaku hasil atau nilai yang telah didapat atas tindakannya. Sedangkan menurut Thahir \& Hidriyanti, (2014), hasil belajar adalah pola tindakan, nilai, arti, dan sikap. Pendapat tersebut diperkuat oleh Sudjana, (2014), yang menjelaskan bahwa hasil belajar merupakan berubahnya sikap seseorang yang diperoleh secara menetap, fungsional, positif, dan disadari guna mencari tahu berhasil tidaknya tujuan pembelajaran. Pendidik perlu mengadakan tes tertulis diakhir proses pembelajaran. Penilaian formatif digunakan untuk mengetahui sejauh mana siswa telah menguasai tujuan pembelajaran yang ingin dicapai.

Subakti (2019) menjelaskan bahwa Bahasa Indonesia dapat dijadikan tolok ukur kemampuan berpikir seseorang baik masih anak-anak, remaja, hingga dewasa. Hal ini dapat dilakukan dengan cara membiasakan diri di dalam proses pembelajaran Bahasa Indonesia secara umum di sekolah khususnya pendidikan dasar. Subakti (2020) memaparkan secara terperinci bahwa proses pembelajaran Bahasa Indonesia harus dipahami secara menyeluruh dan seksama agar memudahkan lawan bicara dalam memahami apa yang dibicarakan. Untuk itu proses pembelajaran Bahasa Indonesia di kelas tinggi pada sekolah dasar harus dilakukan secara berkesinambungan.

\section{METODE}

Penelitian ini menggunakan desain penelitian ex post facto di mana peneliti berusaha untuk menentukan penyebab atau alasan untuk keberadaan perbedaan dalam perilaku atau status dalam kelompok individu. Penelitian ex post facto dilaksanakan untuk meneliti suatu peristiwa di mana peneliti tidak dapat mengendalikan variabel bebas secara langsung atau tidak dapat memanipulasi variabel bebas. Penelitian ini dilakukan untuk meneliti suatu peristiwa yang telah terjadi kemudian mengamati ke belakang tentang faktor-faktor yang dapat menyebabkan timbulnya kajian tersebut adalah penelitian ex post facto (Emzir, 2015).

Metode penelitian kuantitatif dapat diartikan sebagai metode penelitian yang berlandaskan pada filsafat positivisme, dipakai untuk meneliti pada 
250 Pengaruh Bimbingan Belajar terhadap Hasil Belajar Bahasa Indonesia Siswa Kelas Tinggi Sekolah Dasar di Kota Samarinda- Hani Subakti, Eka Selvi Handayani

DOI: https://doi.org/10.31004/basicedu.v5i1.648

populasi atau sampel tertentu, teknik pengumpulan sampel pada umumnya dilakukan secara random, pengumpulan data menggunakan instrumen penelitian, analisis data bersifat kuantitatif atau statistik dengan tujuan untuk menguji hipotesis yang telah ditetapkan (Sugiyono, 2013). Sedangkan menurut Wiratna (2012) penelitian kuantitatif yang menghasilkan penemuanpenemuan memakai teknik statistik ataupun pengukuran.

Penelitian yang didasari pendekatan deduktif-induktif, berarti penelitian tersebut berjenis kuantitatif. Penelitian kuantitatif berangkat dari suatu kajian teori, pendapat dari ahli, ataupun pemahaman peneliti berdasarkan pengalaman di lapangan. Selanjutnya dikembangkan menjadi permasalahan serta penyelasaian yang diajukan untuk memperoleh kebenaran dalam bentuk dukungan data. Desain penelitian ini terdapat dua variabel, variabel bebas (X) bimbingan belajar, sedangkan variabel terikat (Y) hasil belajar.

Penelitian dilakukan di SD Negeri 002 Sungai Pinang yang beralamat di Jalan Pelita, Kelurahan Sungai Pinang Dalam, Kecamatan Sungai Pinang, Kota Samarinda. Waktu pelaksanaan penelitian sejak bulan April sampai dengan bulan Juni tahun 2020.

Sofyan (2014) menyatakan bahwa data merupakan bahan yang perlu diolah sehingga mendapatkan berita atau keterangan yang menunjukkan fakta atau juga dapat diartikan data merupakan kumpulan fakta yang dapat dipercaya kebenarannya sehingga digunakan sebagai dasar untuk menarik kesimpulan. Ada sumber data yang digunakan dalam penelitian ini yakni:

1. Data primer yaitu dijadikan satu sendiri oleh peneliti langsung dari sumber pertama.

2. Data sekunder yakni dipakai oleh kelompok yang bukan pembuatnya.

Populasi yakni tempat yang di dalamnya berupa objek/subjek yang punya kualitas dan karakteristik tertentu yang ditetapkan peneliti untuk dipelajari selanjutnya ditarik kesimpulan (Sugiyono, 2013). Berdasarkan pernyataan tersebut, keseluruhan dari objek yang akan diteliti merupakan anggota yang berada di satu tempat atau wilayah. Adapun yang menjadi target yaitu siswa kelas V SD Negeri 002 Sungai Pinang yang mengikuti bimbingan belajar.

Sugiyono (2018) menyatakan bahwa sampel merupakan bagian dari jumlah yang dipunyai oleh populasi tersebut. Sedangkan menurut Arikunto (2013) menyatakan bahwa sampel merupakan bagian dari anggota yang diteliti. Cara penentuan sampel yaitu dengan total sampling, yaitu penentuan sampel untuk tujuan tertentu cara ini digunakan guna memilih secara sengaja untuk disesuaikan dengan tujuan penelitian (Bimo, 2010).

Instrumen penelitian merupakan bantuan yang dipakai guna mengukur kejadian alam ataupun sosial yang diamati secara saksama yang disebut dalam variabel penelitian (Sugiyono, 2013). Alat yang digunakan untuk pengumpulan data yaitu lembar angket dan gawai. Lembar angket digunakan untuk disebarkan pada siswa dan gawai digunakan sebagai alat dokumentasi. Pada penelitian ini, peneliti menggunakan angket yang 
disebarkan pada siswa kelas V di SD Negeri 002 Sungai Pinang. Untuk mengumpulkan data lebih mudah dan hasilnya lebih cermat penelitian ini menggunakan angket dengan pengukuran skala likert sehingga data lebih mudah diolah.

Angket penelitian menggunakan alat ukur skala likert yang dipakai guna melihat pendapat orang mengenai kejadian sosial (Sugiyono, 2013). Di dalam angket skala likert terdapat lima alternatif jawaban yang tersedia berisi skor.

\section{Tabel 1. Skala Likert}

\begin{tabular}{|l|c|c|}
\hline \multirow{2}{*}{ Alternatif } & \multicolumn{2}{|c|}{ Skor } \\
\cline { 2 - 3 } & $(+)$ & $(-)$ \\
\hline $\begin{array}{l}\text { Sangat Setuju } \\
(\text { SS) }\end{array}$ & 5 & 1 \\
\hline Setuju (ST) & 4 & 2 \\
\hline $\begin{array}{l}\text { Ragu-ragu } \\
(\text { RG) }\end{array}$ & 3 & 3 \\
\hline $\begin{array}{l}\text { Tidak Setuju } \\
\text { (TS) }\end{array}$ & 2 & 4 \\
\hline $\begin{array}{l}\text { Sangat Tidak } \\
\text { Setuju (STS) }\end{array}$ & 1 & 5 \\
\hline
\end{tabular}

Cara menyusun instrumen adalah variabelvariabel tersebut diberikan definisi operasionalnya. Setelah itu dijabarkan menjadi butir-butir pernyataan yang akan diuji keefektifannya dengan cara uji coba angka yang berisi butir-butir pernyataan dari hasil penjabaran indikator yang telah ditentukan (Sugiyono, 2013).

Peneliti melakukan uji validitas dan realibilitas untuk menguji instrumen pernyataan apakah valid atau reliabel.

\section{Uji Validitas}

Instrumen valid ketika instrumen bisa menilai suatu hal secara benar pada apa yang akan dinilai. Melakukan uji validitas untuk mencari ketepatan (validitas) tiap item instrumen. Uji validitas dalam penelitian ini menggunakan aplikasi SPSS 23. Item angket dikatakan valid jika nilai $r_{\text {hitung }}>r_{\text {tabel }}$ pada nilai signifikan sebaliknya, item dikatakan tidak valid jika nilai $r_{\text {hitung }}<r_{\text {tabel }}$ (Sugiyono, 2013).

\section{Uji Reliabilitas}

Uji reabilitas yang digunakan untuk menguji keabsahan dalam data penelitian (Sugiyono, 2013). Jika objek yang diteliti valid pasti reliabel tetapi jika objek reliabel belum tentu valid. Variabel yang dinyatakan reliabel jika nilai cronbach alpha $>0,7$.

Mengumpulkan data dengan berbagai peraturan, berbagai sumber, dan berbagai cara. Pengumpulan data menggunakan sumber primer dan sumber sekunder, yaitu sumber primer merupakan sumber data secara langsung memberikan data kepada pengumpul data sedangkan sumber sekunder tidak langsung memberikan data pada pengumpul data (Sugiyono, 2013). Penelitian ini menggunakan teknik pengumpulan data dengan dua teknik yakni menyebarkan angket dan dokumentasi.

Analisis linier sederhana yang akan dibantu dengan aplikasi SPSS 23. Sebelum melakukan teknik analisis data, instrumen lebih dahulu diuji prasyarat untuk membuktikan hipotesis tersebut, melalui:

1. Uji normalitas, guna melihat angket yang disebarkan pada siswa, apakah angket tersebut bersifat normal atau tidak.

2. Uji linieritas, bertujuan mencari tahu apakah dua variabel memiliki hubungan yang 
252 Pengaruh Bimbingan Belajar terhadap Hasil Belajar Bahasa Indonesia Siswa Kelas Tinggi Sekolah Dasar di Kota Samarinda- Hani Subakti, Eka Selvi Handayani

DOI: https://doi.org/10.31004/basicedu.v5i1.648

signifikan. Uji liniearitas biasa digunakan sebagai prasyarat dalam analisis korelasi ataupun regresi linear, pengujian linear pada aplikasi SPSS dengan menggunakan Test Of Linearity dengan taraf singnifikansi.

3. Uji hipotesis, yaitu mengambil hasil akhir berdasarkan analisis data, keputusan dari uji hipotesis selalu dibuat berdasarkan pengujian hipotesis nol.

\section{HASIL DAN PEMBAHASAN}

Penyebaran angket penelitian pengaruh bimbingan belajar terhadap hasil belajar Bahasa Indonesia kelas tinggi pada siswa kelas $\mathrm{V}$ yang berlokasi di SD Negeri 002 Sungai Pinang Kota Samarinda. Sebelum instrumen penelitian disebarkan terlebih dahulu dilakukan pengujian pada instrumen penelitian guna mengetahui instrumen penelitian layak disebarkan atau tidak. Uji validitas yang dilakukan peneliti dengan angket bimbingan belajar dan angket hasil belajar Bahasa Indonesia yang setiap angket berjumlah 20 butir pernyataan.

Tabel 2. Validitas Bimbingan Belajar

\begin{tabular}{|c|c|c|c|}
\hline No & $r_{\text {tabel }}$ & $r_{\text {hitung }}$ & Status \\
\hline 1 & \multirow{11}{*}{0,412} & 0,781 & Valid \\
\hline 2 & & 0,796 & Valid \\
\hline 3 & & 0,834 & Valid \\
\hline 4 & & 0,731 & Valid \\
\hline 5 & & 0,869 & Valid \\
\hline 6 & & 0,649 & Valid \\
\hline 7 & & 0,853 & Valid \\
\hline 8 & & 0,436 & Tidak Valid \\
\hline 9 & & 0,728 & Valid \\
\hline 10 & & 0,617 & Valid \\
\hline 11 & & 0,738 & Valid \\
\hline 12 & \multirow{3}{*}{0,412} & 0,665 & Valid \\
\hline 13 & & 0,748 & Valid \\
\hline 14 & & 0,597 & Valid \\
\hline
\end{tabular}

\begin{tabular}{|c|c|c|}
\hline 15 & 0,000 & Tidak Valid \\
\hline 16 & 0,677 & Valid \\
\hline 17 & 0,538 & Valid \\
\hline 18 & 0,628 & Valid \\
\hline 19 & 0,331 & Tidak Valid \\
\hline 20 & 0,819 & Valid \\
\hline
\end{tabular}

Dapat dilihat tabel berikut bahwa 17 item angket bimbingan belajar dinyatakan valid dan 3 item angket dikatakan tidak valid.

Tabel 3. Validitas Hasil Belajar Bahasa Indonesia

\begin{tabular}{|c|c|c|c|}
\hline No & $r_{\text {tabel }}$ & $r_{\text {hitung }}$ & Status \\
\hline 1. & \multirow{20}{*}{0,412} & 0,625 & Valid \\
\hline 2. & & 0,249 & Tidak Valid \\
\hline 3. & & 0,534 & Valid \\
\hline 4. & & 0,376 & Tidak Valid \\
\hline 5. & & 0,553 & Valid \\
\hline 6. & & 0,461 & Tidak Valid \\
\hline 7. & & 0,399 & Tidak Valid \\
\hline 8. & & 0,398 & Tidak Valid \\
\hline 9. & & 0,601 & Valid \\
\hline 10. & & 0,588 & Valid \\
\hline 11. & & 0,408 & Tidak Valid \\
\hline 12. & & 0,670 & Valid \\
\hline 13. & & 0,635 & Valid \\
\hline 14. & & 0,674 & Valid \\
\hline 15. & & 0,713 & Valid \\
\hline 16. & & 0,654 & Valid \\
\hline 17. & & 0,657 & Valid \\
\hline 18. & & 0,666 & Valid \\
\hline 19. & & 0,676 & Valid \\
\hline 20. & & 0,588 & Valid \\
\hline
\end{tabular}

Dapat dilihat dari tabel di atas bahwa 14 item angket hasil belajar Bahasa Indonesia dinyatakan valid dan 6 item angket dinyatakan tidak valid.

Setelah validitas dilakukan, kemudian melihat ketetapan dari kedua angket maka dilakukan uji reliabilitas, uji reliabilitas dilakukan bertujuan mengetahui kosistensi angket kapan pun disajikan. Pada uji reliabilitas dasar pengambilan 
253 Pengaruh Bimbingan Belajar terhadap Hasil Belajar Bahasa Indonesia Siswa Kelas Tinggi Sekolah Dasar di Kota Samarinda- Hani Subakti, Eka Selvi Handayani

DOI: https://doi.org/10.31004/basicedu.v5i1.648

keputusan dikatakan reliabel bila nilai koefisien reliabilitas > nilai Cronbach's Alpha yaitu 0,7.

Nilai reliabilitas diangket bimbingan belajar didapat nilai $r=0,937$. Berikutya dibandingkan menggunakan nilai Cronbach's Alpha yaitu 0,7 maka hasil dari uji reliabilitas dikatakan reliabel dan angket bimbingan belajar bisa disebarkan.

Reliabilitas diangket hasil belajar didapat nilai $r=0,901$. Kemudian dibandingkan dengan nilai Cronbach's Alpha yaitu 0,7 hingga pernyataan angket hasil belajar bisa dipakai pada penelitian.

Uji normalitas dilakukan guna mengetahui apakah data yang dipakai normal atau tidak, untuk mengetahui data yang dipakai berdisitribusi normal atau tidak cukup dibandingkan saja nilai signifikansi (Asymp Sig 2-tailed). Jika nilai sigifikansi lebih besar dari nilai signifikansi 0,05 artinya data berdistribusi normal.

Tabel 4. Uji Normalitas

\begin{tabular}{|c|c|c|}
\hline Variabel & Sig & Keterangan \\
\hline $\begin{array}{ll}\text { Bimbingan } & \text { Belajar } \\
\text { terhadap Hasil } & \text { Belajar } \\
\text { Bahasa Indonesia }\end{array}$ & 0,200 & Normal \\
\hline
\end{tabular}

Data tabel berikut menunjukkan nilai signifikan lebih besar dari 0,05 sama dengan berdistribusi normal.

Pada uji linearitas menggunakan program SPSS 23 untuk pengambilan keputusan apabila nilai signifikansi from linearity $>0,05$ adanya keterkaitan yang sama pada bimbingan belajar dengan hasil belajar Bahasa Indonesia. Berdasarkan pengolahan data SPSS kemudian diambil dari deviation from linearity diperoleh nilai bimbingan belajar dan hasil belajar Bahasa Indonesia sebesar 0,465. Jadi diketahui 0,465 > 0,05 diambil keputusan ada hubungan linear pada bimbingan belajar terhadap hasil belajar.

Uji hipotesis dicari menggunakan uji t, uji hipotesis berguna dalam menjawab hasil dari dugaan sementara, setelah melakukan uji normalitas dan uji linearitas akan melakukan analisis data untuk menguji hipotesis. Perhitungan uji hipotesis pada angket bimbingan belajar serta hasil belajar Bahasa Indonesia diperoleh hasil thitung adalah 4,451 $t_{\text {tabel }} 1,701$ ditulis $t_{\text {hitung }}>\mathrm{t}_{\text {tabel }}(4,451>$ 1,701) berarti $\mathrm{Ha}$ diterima.

Bimbingan belajar salah satu kegiatan yang dilakukan guna membantu siswa menghadapi masalah di dalam belajar, bimbingan belajar dapat diberikan baik individu atau kelompok yang pelaksanaannya dilakukan di luar jam pelajaran di sekolah. Bimbingan belajar sendiri mempunyai tujuan untuk meningkatkan nilai siswa. Sementara itu, hasil belajar yaitu pencapaian siswa baik dalam bentuk berubahnya perilaku yang cenderung menetap dari kognitif, akfektif dan psikomotor khususnya bahasa Indonesia. Secara umumnya hasil belajar Bahasa Indonesia dipengaruhi dua faktor yaitu internal atau dari diri siswa baik dari segi aspek fisiologis, kesehatan tubuh, serta kondisi lima indera. Faktor dari luar atau eksternal yaitu dari lingkup tempat tinggal, pengaruh teman bermain, dan cuaca pada saat melakukan kegiatan pembelajaran.

Angket mengenai bimbingan belajar terhadap hasil belajar Bahasa Indonesia siswa kelas tinggi memiliki jumlah item angket 20 butir pernyataan. Kemudian disebarkan secara 
254 Pengaruh Bimbingan Belajar terhadap Hasil Belajar Bahasa Indonesia Siswa Kelas Tinggi Sekolah Dasar di Kota Samarinda- Hani Subakti, Eka Selvi Handayani

DOI: https://doi.org/10.31004/basicedu.v5i1.648

daring/online melalui google form pada siswa kelas VA yang berjumlah 14 siswa dan kelas VB berjumlah 16 siswa yang kemudian digabungkan menjadi satu dengan jumlah akhir populasi responden 30 siswa. Melalui perhitungan uji hipotesis di kelas VA dan B, maka didapatkan hasil bimbingan belajar dan hasil belajar Bahasa Indonesia $t_{\text {hitung }}>\mathrm{t}_{\text {tabel }}(4,451>1,701)$ yang dapat diartikan dapat disimpulkan hasil angket bimbingan belajar dan hasil belajar Bahasa Indonesia dapat diterima.

\section{SIMPULAN}

Peneliti telah melakukan uji validitas instrumen sebelum angket disebarkan dengan pengujian pada instrumen penelitian guna mengetahui instrumen penelitian layak disebarkan atau tidak. Pengujian instrumen penelitian dengan menggunakan uji validitas dan uji reliabilitas. Angket yang memenuhi syarat uji validitas dan reliabilitas selanjutnya disebarkan melalui google form. Setelah responden mengisi angket penelitian selanjutnya dilakukan perhitungan dengan uji normalitas untuk mengetahui apakah data yang digunakan berdistribusi normal atau tidak. Untuk mengetahuinya peneliti menggunakan uji normalitas kolmogorov-smirnov dengan syarat nilai signifikansi di atas 0,05 melalui bantuan IBM SPSS 23. Diperoleh nilai signifikansi 0,200 yakni lebih besar dari 0,05 yang artinya angket normal.

Angket yang telah normal berikutnya digunakan peneliti untuk menguji linearitas menggunakan program SPSS 23 sebagai dasar pengambilan keputusan. Apabila nilai signifikansi from linearity $>0,05$ maka terdapat hubungan yang linear antara bimbingan belajar dengan hasil belajar Bahasa Indonesia diambil dari deviation from linearity diperoleh nilai bimbingan belajar sebesar 0,465 . Jadi diketahui $0,465>0,05$, maka diambil keputusan adanya hubungan yang linear antara bimbingan belajar terhadap hasil belajar Bahasa Indonesia. Angket yang telah lulus uji linearitas berikutnya diuji hipotesisnya. Perhitungan uji hipotesis yang dilakukan pada angket bimbingan belajar dan hasil belajar Bahasa Indonesia dan diperoleh hasil $t_{\text {hitung }}$ adalah 4,451 dengan $t_{\text {tabel }} 1,701$ ditulis $t_{\text {hitung }}>t_{\text {tabel }}(4,451>$ 1,701) berarti $\mathrm{Ha}$ diterima. Melalui hasil angket bimbingan belajar dan hasil belajar Bahasa Indonesia diambil kesimpulan angket diterima, maka terdapat pengaruh bimbingan belajar terhadap hasil belajar Bahasa Indonesia di kelas tinggi sekolah dasar pada SD Negeri 002 Sungai Pinang tahun pembelajaran 2019/2020. Dengan demikian diambil kesimpulan akhir bahwa terdapat pengaruh bimbingan belajar terhadap hasil belajar Bahasa Indonesia kelas tinggi sekolah dasar pada SD Negeri 002 Sungai Pinang tahun pembelajaran 2019/2020 dengan mengarah pada hipotesis yang diterima.

\section{DAFTAR PUSTAKA}

Arikunto, Suharsimi. (2013). Prosedur Penelitian. Rineka Cipta: Surabaya.

Bimo, W. (2010). Bimbingan dan Konseling. RajawaliPers: Yogjakarta.

Dita Septi, A. (2019). Pengaruh Bimbingan Belajar Terhadap Kondisi Ekonomi Orang Tua Terhadap Hasil Belajar Siswa Kelas IV MI'MAARIF Cekok Badadan Ponorogo Tahun Ajaran 2016/2017, 6(1), $1-46$. 
255 Pengaruh Bimbingan Belajar terhadap Hasil Belajar Bahasa Indonesia Siswa Kelas Tinggi Sekolah Dasar di Kota Samarinda- Hani Subakti, Eka Selvi Handayani

DOI: https://doi.org/10.31004/basicedu.v5i1.648

https://doi.org/10.1016/j.surfcoat.2019.12 5084

Emzir. (2015). Metodelogi Penelitian Pendidikan Kuantitatif dan Kualitatif. Rajawali Pers: Jakarta.

Fauziyyah, N. (2017). Pengaruh Keikutsertaan Siswa Mengikuti Bimbingan Belajar Terhadap Hasil Belajar Ekonomi di Kelas XII IPS SMA NEGERI 5 Depok Tahun Ajaran 2016/2017, 43. https://doi.org/10.1017/CBO9781107415 324.004

Hamalik, Oemar. (2011). Proses Belajar Mengajar. Bumi Aksara: Jakarta.

Handyani, Eka Selvi dan Hani Subakti. (2020). Pengaruh Disiplin Belajar terhadap Hasil Belajar Bahasa Indonesia di Sekolah Dasar. Jurnal Basicedu, Vol $\begin{array}{llll}\text { (5) } & \text { No } & 1 & \text { (2020) 151-164 }\end{array}$ https://doi.org/10.31004/basicedu.v5il.63 3.

Jihad, A. (2013). Evalusi Pembelajaran. Multi Pressindo: Bandung.

Purwanto, Ngalim M. (2015). Psikologi Pendidikan. Remaja Rosdakarya: Yogjakarta.

Subakti, Hani. (2019). 8 Konsepsi Landasan Bahasa Indonesia di Perguruan Tinggi. Parepare: Kaaffah Learning Center.

Subakti, Hani. (2019). Pengembangan Pembelajaran Menulis Cerita Pendek dengan Model Mind Mapping pada Siswa Kelas XI SMK Negeri 11 Samarinda Tahun Pembelajaran 2018 2019. Vol. 2, No. 2, Desember 2019. https://doi.org/10.36277/basataka.v2i2.67.

Subakti, Hani. (2020). Hasil Belajar Muatan Bahasa Indonesia Tema Peduli Terhadap Makhluk Hidup Menggunakan Reward Pada Kelas IV SDN 023 Samarinda Utara. Vol.03 No. 01, 1-9, Juni 2020. https://doi.org/10.36277/basataka.v3i1.80.

Subakti, Hani. (2020). Hasil Belajar Mauatan
Bahasa Indonesia Tema Lingkungan Sahabat Menggunakan Media Spining Wheel Kelas V SDN 007 Samarinda Ulu. Disastra: Jurnal Pendidikan Bahasa dan Sastra Indonesia, 2(2),192-206 http://ejournal.iainbengkulu.ac.id/index.p $\mathrm{hp} /$ disastra. Bengkulu. Institut Agama Islam Negeri Bengkulu.

Sudjana, Nana. (2014). Dasar-Dasar Proses Belajar Mengajar. Sinar Baru Algensindo: Bandung.

Sofyan S, W. (2014). Konseling Indivual Teori dan Praktek. Alfabeta: Jakarta.

Sugiyono. (2018). Metode Penelitian Pendidikan Pendekatan Kualitatif, Kuantitatif, dan $R \& D$. Alfabeta: Bandung.

Wiratna, Sujarweni. (2012). Statistika untuk Penelitian. Graha Ilmu: Yogyakarta.

Yusuf, S. (2013). Landasan Bimbingan dan Konseling. Remaja Rosdakarya: Jakarta. 